\title{
ATIVIDADE ANTIMICROBIANA DE MÉIS COMERCIALIZADOS NA REGIÃO DOS CAMPOS GERAIS - PARANÁ
}

\section{ANTIMICROBIAL ACTIVITY OF MARKETED HONEYS FROM REGION OF CAMPOS GERAIS - PARANÁ}

\author{
BORSATO, Débora Maria'1, CRUZ, Michele Cristina Rodrigues da², \\ ALMEIDA, Mareci Mendes de ${ }^{3}$ \\ ${ }^{1}$ Mestre em Ciência e Tecnologia de Alimentos (dmborsato@yahoo.com.br) \\ ${ }^{2}$ Acadêmica do curso de Engenharia de Alimentos da Universidade Estadual de Ponta Grossa \\ (chelecruzdez@yahoo.com.br) \\ ${ }^{3}$ Professora Adjunto do Departamento de Engenharia de Alimentos da Universidade Estadual de Ponta Grossa \\ (mareci@uepg.br) \\ REC:02/09 AC: 03/09
}

\begin{abstract}
RESUMO:
O mel é um alimento muito apreciado, em função do seu sabor característico e do seu considerável valor nutritivo. Sua qualidade nutricional, devida à presença de vitaminas e minerais, seu valor energético elevado, suas propriedades medicinais, como a ação antioxidante e a atividade anti-séptica, e suas propriedades sensoriais têm atraído inúmeros consumidores. Todos os fatores químicos e físicos fazem com que as propriedades terapêuticas do mel sejam únicas, sendo utilizado como um potente agente antimicrobiano. O objetivo deste trabalho foi avaliar a ação antimicrobiana de méis $(n=13)$ comercializados na região dos Campos Gerais Paraná. A atividade antimicrobiana revelou um comportamento variável, tanto no que se refere à sensibilidade dos microrganismos (Staphylococcus aureus e Escherichia coli), quanto ao poder antimicrobiano das amostras testadas.
\end{abstract}

Palavras-chave: mel, atividade antimicrobiana, Staphylococcus aureus e Escherichia coli

\begin{abstract}
:
Honey is a very traditional food. In additional, several customers have been daily used a large number of honeys due to their particular nutritional quality (e.g. vitamins and minerals), high energy values, their medicinal uses (as antioxidant and antiseptic properties) and their sensorial features. Due to physical and chemical properties, honey is used as a potent antimicrobial agent. The aim of this work was to evaluate the antimicrobial activity of honeys $(n=13)$ marketed in the region of Campos Gerais - Paraná. An unrelated behavior was verified when sensibility of the microorganisms (Staphylococcus aureus and Escherichia coli) and antimicrobial activity were studied.
\end{abstract}

Key words: honey, antimicrobial activity, Staphylococcus aureus and Escherichia coli

\section{INTRODUÇÃO}

O mel pode manter-se preservado à deterioração por longos períodos de tempos. Essa sua característica intrínseca se deve a sua atividade antimicrobiana, que pode variar de acordo com a sua origem floral (SATO \& MIYATA, 2000).

Existem vários fatores que podem contribuir para a propriedade antimicrobiana do mel, dentre os quais: baixa atividade de água $\left(A_{w}\right)$, alta pressão osmótica, baixo 
valor de $\mathrm{pH}$, sistema glucose-oxidase, com a formação de peróxido de hidrogênio, alta taxa carbono/nitrogênio, baixo potencial redox, relacionado ao alto conteúdo de açúcares redutores, baixo conteúdo de proteínas, presença de agentes químicos e substâncias voláteis (HOOPER, 1976; MOLAN, 1996; NATIONAL HONEY BOARD, 2006; WESTON, 2000; WHITE, 1979).

A resistência bacteriana aos antibióticos continua sendo uma preocupação na área da saúde por todo o mundo. Desde que a utilização de antibióticos foi amplamente difundida, há 50 anos, as bactérias têm progressivamente desenvolvido resistência (HSUEH et al., 2005). Com isso, estudos têm sido realizados com o objetivo de desenvolver novos compostos que possam ser usados com a finalidade antimicrobiana, além da terapia antibiótica convencional.

O objetivo deste trabalho foi analisar a atividade antimicrobiana de méis comercializados na região dos Campos Gerais - Paraná.

\section{MATERIAL E MÉTODOS}

As análises das amostras de méis, produzido por Apis mellifera L., foram realizadas nos laboratórios do Centro de Tecnologia de Alimentos do Departamento de Engenharia de Alimentos da Universidade Estadual de Ponta Grossa.

\subsection{Material}

Para a realização das análises, as amostras de méis foram obtidas dos produtores dos municípios de Ponta Grossa, Castro e Ortigueira, pertencentes à Região dos Campos Gerais, sendo imediatamente armazenadas sob refrigeração. Foram coletadas 13 amostras de méis, as quais foram submetidas previamente à análise polínica para a identificação de sua origem botânica (dados não mostrados).

\subsection{Métodos}

A determinação da atividade antimicrobiana das amostras de méis foi realizada em Ágar Müeller-Hinton através da prova de sensibilidade por diluição em Ágar (KONEMAN et al., 2001) e foram utilizados os microrganismos Escherichia coli e Staphylococcus aureus.

Para padronização do inóculo os microrganismos foram inoculados em placas de petrie incubados em estufa bacteriológica a $35 \square$ C por $24 \mathrm{~h}$, as colônias de bactérias foram transferidas para solução salina estéril $(0,9 \%)$ até obtenção de turvação, correspondente ao tubo no 5 da escala McFarland (KONEMAN et al., 2001).

Para o preparo do meio de cultura, todo o material utilizado foi esterilizado e o procedimento foi realizado em câmara de fluxo laminar. Foram utilizadas concentrações de mel de 10, 15, 20, 25 e 30\% para um volume final $20 \mathrm{~mL}$, o mel foi incorporado ao meio de cultura Ágar Mueller-Hinton a uma temperatura de $45 \square \mathrm{C}$ e vertido na placa. Com o Agar já solidificado, foram espalhados 100 ì da suspensão bacteriana com alça de Drigalski. As placas foram identificadas e levadas à estufa a 35 $\square \mathrm{C}$ por 18-20h e o crescimento bacteriando foi avaliado em UFC. $\mathrm{mL}^{-1}$, sendo apresentadas os valores médios dos resultados obtidos. 
Como controles positivos, foram preparadas placas para cada microrganismo somente com o meio de cultura, sem a adição do mel, utilizando discos de antibióticos (ampicilina). Adicionalmente, foram preparadas placas contendo solução de glucose e frutose, em iguais proporções, com diferentes concentrações (15, 20, 25 e 30 \%), adicionadas a $20 \mathrm{~mL}$ de Ágar Müeller-Hinton.

\section{RESULTADOS E DISCUSSÃO}

Os resultados para a atividade antimicrobiana das amostras de méis estão representados na Tabela 1.

TABELA1- POTENCIAL ANTIMICROBIANO DAS AMOSTRAS DE MÉIS, COMERCIALIZADAS NA REGIÃO DOS CAMPOS GERAIS - PR, DILUÍDAS A 10, 15, 20,25 E $30 \%$.

\begin{tabular}{lccccccccccc}
\hline \multirow{2}{*}{ Amostra } & \multicolumn{4}{c}{ Escherichia coli } & \multicolumn{5}{c}{ Staphylococcus aureus } \\
\cline { 2 - 11 } & $\mathbf{1 0} \%$ & $\mathbf{1 5 \%}$ & $\mathbf{2 0} \%$ & $\mathbf{2 5} \%$ & $\mathbf{3 0} \%$ & $\mathbf{1 0} \%$ & $\mathbf{1 5 \%}$ & $\mathbf{2 0} \%$ & $\mathbf{2 5} \%$ & $\mathbf{3 0 \%}$ \\
\hline $\mathbf{1}$ & $>300$ & 275 & - & - & - & $>300$ & - & - & - & - \\
$\mathbf{2}$ & $>300$ & $>300$ & $>300$ & $>300$ & $>300$ & $>300$ & $>300$ & $>300$ & $>300$ & $>300$ \\
$\mathbf{3}$ & $>300$ & $>300$ & - & - & - & $>300$ & $>300$ & 12 & - & - \\
$\mathbf{4}$ & $>300$ & $>300$ & $>300$ & $>300$ & - & $>300$ & $>300$ & $>300$ & $>300$ & $>300$ \\
$\mathbf{5}$ & $>300$ & $>300$ & $>300$ & $>300$ & $>300$ & $>300$ & $>300$ & $>300$ & $>300$ & $>300$ \\
$\mathbf{6}$ & $>300$ & $>300$ & $>300$ & $>300$ & $>300$ & $>300$ & $>300$ & $>300$ & $>300$ & $>300$ \\
$\mathbf{7}$ & $>300$ & - & - & - & - & 1 & - & - & - & - \\
$\mathbf{8}$ & $>300$ & $>300$ & 282 & - & - & 113 & 17 & - & - & - \\
$\mathbf{9}$ & $>300$ & - & - & - & - & 48 & - & - & - & - \\
$\mathbf{1 0}$ & $>300$ & - & - & - & - & 142 & - & - & - & - \\
$\mathbf{1 1}$ & $>300$ & - & - & - & - & $>300$ & 16 & 11 & 9 & - \\
$\mathbf{1 2}$ & $>300$ & $>300$ & $>300$ & 20 & 5 & $>300$ & $>300$ & $>300$ & 20 & 1 \\
$\mathbf{1 3}$ & $>300$ & $>300$ & 15 & 7 & - & $>300$ & 12 & 9 & 4 & 3 \\
\hline
\end{tabular}

Nota: (-) representa a ausência do crescimento bacteriano; valores de 1 a $>300$ correspondem a UFC. $\mathrm{mL}^{-1}$.

De acordo com os resultados demonstrados na Tabela 1, para a maioria das amostras, houve uma maior atividade antimicrobiana à medida que a concentração de mel utilizada foi elevada. As amostras 7 (mel de eucalipto), 9 (mel heterofloral) e 10 (mel de laranjeiras) inibiram por completo o crescimento de ambos os microrganismos testados, quando as concentrações utilizadas foram iguais ou superiores a $15 \%$. Entretanto, as amostras 2 (mel de bracatinga), 5 (mel de acácia) e 6 (mel de laranjeiras e eucalipto) não revelaram atividade antimicrobiana em nenhuma das concentrações estudadas. 
Esses resultados indicam que os microrganismos estudados são sensíveis ao poder antimicrobiano do mel nas concentrações avaliadas, mas não para todas as amostras. De acordo com Sato \& Myiata (2000), a propriedade antimicrobiana pode variar de acordo com a origem floral do mel. Entretanto, ao analisar as amostras, verifica-se que os méis monoflorais contendo apenas eucalipto ou laranjeiras, tiveram um potencial antimicrobiano elevado. Porém, a amostra 6, contendo laranjeira e eucalipto, não apresentou potencial antimicrobiano, nas concentrações estudadas. Dessa forma, outros parâmetros devem ser considerados, além da origem botânica, para relacionar a atividade antimicrobiana com a composição química do mel.

A amostra 11 (mel heterofloral) revelou um maior poder antimicrobiano frente a E. coli, quando comparado ao $S$. aureus, nas concentrações de $10 \%$ a $25 \%$. Porém, quando a concentração de mel chegou a $30 \%$, os dois microrganismos foram igualmente inibidos. Na amostra 12 (heterofloral) a inibição foi semelhante para ambas as bactérias. A amostra 7 (mel de eucalipto), na concentração de 10\%, apresentou uma inibição maior do crescimento de $S$. aureus. Os resultados obtidos demonstram que há um comportamento variável da atividade antimicrobiana, tanto no que se refere à sensibilidade dos microrganismos ( $S$. aureus e $E$. coll), quanto no poder antimicrobiano dos diferentes tipos de amostras analisadas.

A variação na atividade antimicrobiana pode ser, aparentemente, devida a muitos fatores, como diferenças no solo e nas condições atmosféricas, bem como relacionados ao tipo e fisiologia de cada planta, que contribui para a formação do mel. Pode também ser resultado de diferenças na composição química atribuída a diferentes origens florais e condições ambientais.

No presente estudo, para verificar se a alta concentração de açúcares presentes no mel é capaz, isoladamente, de promover a inibição do crescimento bacteriano, também foi investigada a atividade antimicrobiana de solução de açúcares contendo iguais proporções de glucose e frutose, os resultados demonstraram que a alta pressão osmótica, de modo isolado, não exerceu efeito inibidor do crescimento bacteriano. Os halos de inibição formados nas placas controles foram compatíveis com os encontrados na literatura (KONEMAN et al., 2001), assegurando que as suspensões bacterianas foram padronizadas corretamente.

Diferentes bactérias são responsáveis pela contaminação de ferimentos, pela colonização de feridas e por infecções clínicas, entre eles cita-se $S$. aureus e $E$. coli (BASUALDO et al., 2007). O mel acelera a cicatrização de ferimentos, quando aplicado topicamente ou por administração sistêmica (SUGUNA et al., 1992), promovendo a diminuição rápida de infecções, a supressão da inflamação, a minimização de escaras, bem como o desenvolvimento dos tecido epitelial e granular (MOLAN, 2002). Assim, os resultados obtidos no presente estudo, que evidenciam o potencial antimicrobiano do mel, estão de acordo aos apontados pela literatura. Dessa forma, é possível estabelecer a utilização do mel como um potencial e atóxico tratamento para feridas, desde que atenda a certos critérios, como estar livre de resíduos herbicidas, pesticidas, metais pesados e elementos radioativos; e ser esterilizado para prevenir infecções secundárias (EMSEN, 2007). 


\section{CONCLUSÃo}

A partir dos resultados obtidos foi possível concluir que a maioria das amostras de mel analisadas apresentou atividade antimicrobiana, sendo esta crescente à medida que houve um aumento da concentração de mel utilizada. Os microrganismos estudados apresentaram um comportamento diverso quanto à sua sensibilidade para os diferentes tipos de méis testados.

\section{REFERÊNCIAS}

BASUALDO, C.; SGROY, V.; FINOLA, M. S.; MARIOLI, J. M. Comparison of the antibacterial activity of honey from different provenance against bacteria usually isolated from skin wounds. Veterinary Microbiology, v. 124, p. 375-381, 2007.

EMSEN, I. M. A different and safe method of split thickness skin graft fixation: Medical honey application. Burns, v. 33, p. 782-787, 2007.

HOOPER, T. Guia do Apicultor. [S.I.]: Publicações Europa-América, 1976, p. 223266.

HSUEH, P., CHEN, W., LUH, K. Relationships between anti-microbial use and antimicrobial resistance in Gram-negative bacteria causing nosocomial infections from 1991-2003 at a university hospital in Taiwan. International Journal of Antimicrobial Agents, v. 26, p. 463-472, 2005.

KONEMAN, E. W.; ALLEN, S. D.; JANDA, W. A.; SCHRECKNBERGER, P. C.; WIM, W. C. Jr. Diagnóstico Microbiológico: texto e atlas colorido. 5 ed. Rio de Janeiro: Medsi, 2001, p. 819-828.

MOLAN, P. C.; ALLEN, K. L. The Effect of Gamma-irradiation on the Antibacterial Activity of Honey. Journal of Pharmacy and Pharmacology, v. 48, p. 1206-1209, 1996.

MOLAN, P. C. Honey as an antimicrobial agent. Bee Products. New York: Plenum Press, p. 27-37, 1996.

MOLAN, P. C. Not all honeys are the same for wound healing. European Tissue Repair Society - Bulletin, v. 9, p. 5-6, 2002.

NATIONAL HONEY BOARD. Properties of honey. Disponível em: <http://www.nhb.org/ properties/index.html>. Acesso em 22 mai. 2009.

SATO, T.; MIYATA, G. The Nutraceutical Benefit, Part III: Honey. Nutrition, v. 16, no 6, 2000. 
SUGUNA, L.; CHANDRAKASAN, G.; THOMAS JOSEPH, K. Inûuence of honey on collagen metabolism during wound healing in rats. Journal of Clinical Biochemistry \& Nutrition, v. 13, p. 7-12, 1992.

WESTON, R. J.; BROCKLEBANK, L. K.; LU, Y. Identification and quantitative levels of antibacterial components of some New Zealand honeys. Food Chemistry, v. 70, p. 427-435, 2000.

WESTON, R. J. The contribuition of catalase and others natural products to the antibacterial activity of honey: a review. Food Chemistry, v. 71, p. 235-239, 2000.

WHITE, J. W. Composition of honey. In CRANE, E. Honey. A comprehensive survey. Londres: Heinemann, 1979. p. 157-207 